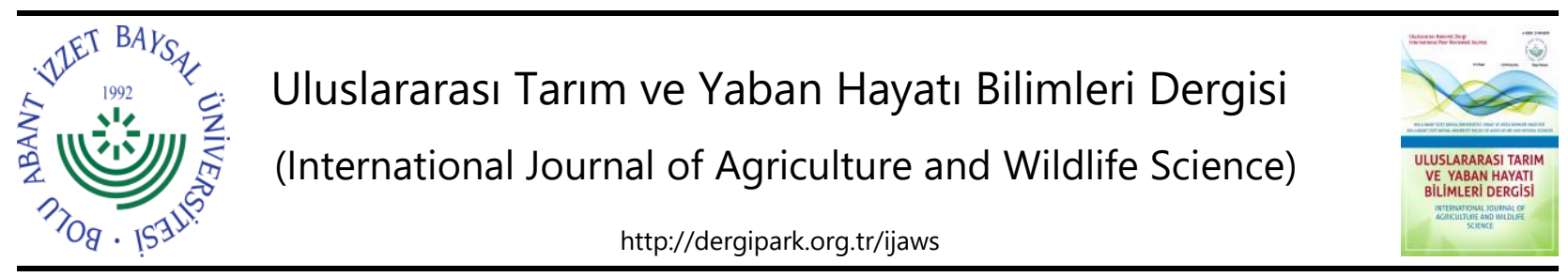

Araştırma Makalesi

\title{
Torba ve Blok Pres Yetiştirme Sistemlerinin Agaricus bisporus Mantarının Verim ve Morfolojik Özellikleri Üzerine Etkisi
}

\author{
Erkan Eren $^{1 *}$ (D) Mehmet Çetin ${ }^{1}$ (D) Aysun Pekşen ${ }^{2}$ \\ ${ }^{1}$ Ege Üniversitesi, Bergama Meslek Yüksek Okulu, Mantarcılık Programı, İzmir \\ ${ }^{2}$ Ondokuz Mayıs Üniversitesi, Ziraat Fakültesi, Bahçe Bitkileri Bölümü, Samsun \\ Geliş tarihi (Received): 27.04.2021 Kabul tarihi (Accepted): 08.06.2021
}

\begin{abstract}
Anahtar kelimeler: Kültür mantarı, verim, kalite, blok pres, torba kültürü

*Sorumlu yazar

erkan.eren@ege.edu.tr

Özet. Çalışmada silindir şekilli geleneksel torbalar ile son yıllarda ülkemizde de yaygın olarak kullanılan blok pres torbalar ile yapılan yetiştiricilik sistemlerinin beyaz şapkalı (Agaricus bisporus) mantarların verim ve morfolojik özelliklerine etkisi incelenmiştir. Torba ve blok pres sistemlerinden elde edilen mantarların ortalama mantar ağırlığı, şapka çapı, sap uzunluğu ve sertlik değerleri bakımından aralarında istatistiksel olarak fark olmadığı, toplam mantar sayısı, şapka yüksekliği, sap çapı ve uzunluğu bakımından ise farkın önemli $(p<0.05)$ olduğu tespit edilmiştir. Blok pres torba sisteminden elde edilen verim değeri (26.58 kg $\left.100 \mathrm{~kg} \mathrm{kompost}^{-1}\right)$, torba sisteminden (22.23 kg 100 $\mathrm{kg} \mathrm{kompost}^{-1}$ ) elde edilen verim değerine göre istatistiksel olarak önemli derecede yüksek bulunmuştur. Blok pres sistemi, torba sistemine göre \%4.35 oranında verim artışı sağlamıştır. Çalışma sonuçları ve iki sistem farklı yönleriyle değerlendirildiğinde blok pres torba sisteminin kullanılması üreticilere önemli avantajlar sağlayacaktır.
\end{abstract}

\section{The Effect of Bag and Block Press Growing Systems on Yield and Morphological Properties of Agaricus bisporus Mushroom}

\section{Keywords:}

Cultivated mushroom, yield, quality, block press, bag cultivation

\begin{abstract}
In this study, the effects of growing systems used with block press bags, which are widely used in our country in recent years, and traditional cylindrical bags on the yield and morphological characteristics of button (Agaricus bisporus) mushroom were investigated. It was determined that the mushrooms obtained from bag and block press systems were not statistically different in terms of average fruit bodies weight, cap diameter, stem length and hardness values, and the difference between them was significant $(p<0.05)$ in terms of total fruit bodies number, cap height, stem diameter and length. The yield value obtained from the block press bag system $(26.58 \mathrm{~kg} 100 \mathrm{~kg}$ compost $^{-1}$ ) was found to be statistically significantly higher than the yield value obtained from the bag system $\left(22.23 \mathrm{~kg} 100 \mathrm{~kg}\right.$ compost $\left.^{-1}\right)$. The block press system provided a $4.35 \%$ increase in yield compared to the bag system. When the results of the study and the two systems are evaluated from different aspects, the use of the block press bag system will provide significant advantages to the producer.
\end{abstract}




\section{GiRiş}

Türkiye'de kültür mantarı üretimi özellikle son 10 yılda hızlı bir gelişim göstermiştir. 1973 yılında kültür mantarı üretim miktarı 80 ton (Erkal ve Aksu, 2000) iken, bu değer 2000'li yıllarda 18.000 ton ve 2018 yılında 65.000 tona yükselmiştir (Eren ve Pekşen, 2019). Türkiye'de kültür mantarı işletmelerinde üretilen kompost ve satılan misel miktarlarına göre tarafımızdan yapılan hesaplamalara göre 2020 yılında ise mantar üretiminin yaklaşık 70.000 ton/yıl seviyesine yükseldiği tespit edilmiştir. Başta Akdeniz, Marmara, Ege ve iç Anadolu bölgelerimizde yaygınlaşmaya başlayan kültür mantarı yetiştiriciliği, son yıllarda hemen hemen tüm bölgelerimizde yapılmaya başlamıştır. Mantar sektörüne verilen desteklerin artması, sektörün gelişmesinde önemli bir etken olmuştur. Ayrıca sektörde beyaz şapkalı mantar dışında farklı mantar türlerinin ticari yetiştiriciliği de yaygınlaşmaktadır. Özellikle istiridye/kayın (Pleurotus ostreatus) mantarının beyaz şapkalı (Agaricus bisporus) mantara oranla daha kolay ve düşük maliyetli üretilebilmesi nedeniyle toplam mantar üretimindeki payının arttığı ve üretimdeki payının \%14 seviyelerine ulaştığı görülmektedir. Bununla birlikte mantar üretimimizin \% 75'ini Agaricus cinsi mantarlar oluşturmaktadır (Eren ve Pekşen, 2019).

Mantar yetiştiriciliği yapısı itibariyle diğer tarımsal yetiştiricilik kollarından oldukça farklıdır. Mantar yetiştiriciliğinde üretim odalarında kompostun yerleştirildiği ranza ve raflar gibi taşıyıcılarla katı sistemde dikey tarım modeli kullanılmaktadır. Bu da birim alandan çok daha fazla ürün alınabilmesini sağlamaktadır. Ranza ve raflarda torba sistem ile yetiştiricilik yapılmakta, son yıllarda ise, blok pres haline getirilmiş misel ekili hazır kompostlar kullanılmaktadır. Günümüzde mantar yetiştiren birçok ülkede torba/blok sisteminin varyasyonları kullanılarak üretim yapılmaktadır (Samp, 2017).

Türkiye'de ticari kültür mantarı yetiştiriciliğine 1980 'li yıllarda başlanmış ve genel olarak torba kültürü olarak da tanımlanan silindir prizma şekline sahip plastik torbalar içerisinde üretimin yapılması tercih edilmiştir (Günay, 1995). Başlangıçta torba sisteminde yaklaşık $60 \mathrm{~cm}$ çapında silindirik plastik torbalarda beyaz şapkalı mantar üretilirken daha sonraki süreçte $45-50 \mathrm{~cm}$ çapında daha küçük torbalarda da üretim yapılmaya başlanmıştır. Yaklaşı $25-40 \mathrm{~cm}$ yüksekliğinde olan bu torbalarda ortalama 10-15 kg kompost bulunmaktadır.

$2000^{\prime} l i$ yıllarda torba sisteminin yanında blok pres adı verilen dikdörtgen prizması şeklinde plastik paketlerde misel ekili kompostların üretim için kullanımına başlanmıştır. Blok pres kompostlar; $35 \times 50 \mathrm{~cm}$ ve $40 \times 60 \mathrm{~cm}$ olmak üzere iki farklı ölçekte oluşturulmuş ve ağırlıklarına göre blok preslerin yükseklikleri ayarlanmıştır. Ortalama $15-25 \mathrm{~cm}$ aralığında yüksekliklere sahip olan bloklarda yaklaşık $12-23 \mathrm{~kg}$ arasında kompost bulunmaktadır.

Ülkemizde beyaz şapkalı mantar üretiminde II. fermantasyonu (Faz II) tamamlamış ve misel ekimi gerçekleştirilmiş bir şekilde hem torba hem de blok pres sistemi kullanılmaktadır. Eren ve ark. (2016) yaptıkları çalışmada Türkiye'de orta ve büyük mantar işletmelerinde pastörizasyon sonrası kompostun \%50 torba, \%40 blok pres ve \%10 kasa sistemi şeklinde paketlendiğini bildirmişlerdir. Son yıllarda büyük işletmelerde torba sisteminin yerini blok pres sisteminin aldığı ve blok pres kullanım oranının yaklaşık \%90 seviyelerine ulaştığı görülmektedir. İşletmeler hangi yetiştirme sistemini kullanacağına; işçilik, işletmenin yapısı, kompost temin ettiği işletmenin üretim şekline göre karar vermektedir. Ancak bu iki yetiştirme sisteminin verim ve mantarın morfolojik özellikleri üzerine etkisinin karşılaştırıldığı bir çalışma bulunmamaktadır. Torba ve blok pres sistemlerinin beyaz şapkalı mantarın verim ve mantar kalitesi üzerine etkilerinin ortaya konması bu karar aşamasında mantar üreticilerine önemli katkı sağlayacaktır.

Bu çalışmada torba ve blok pres yetiştirme sistemlerinin beyaz şapkalı mantarın verim ve verim unsurları ile morfolojik özellikleri üzerine etkileri belirlenmiştir.

\section{MATERYAL VE METOT}

Çalışma iklimlendirmesi bilgisayar kontrollü otomasyon sistemlerine sahip Ege Üniversitesi Bergama Meslek Yüksekokuluna ait üretim odalarında gerçekleştirilmiştir. Denemede Müpa Tarım mantar işletmesi tarafından hazırlanan ve Sylvan A15 miseli ile aşılanmış kompostlar kullanılmıştır. Kompostlar torba ve blok press sistemi olmak üzere 2 farklı şeklinde hazırlanmıştır. Torba sisteminde her bir torba da $12 \mathrm{~kg}$ kompost olacak şekilde toplam 10 poşet kullanılmıştır. Blok pres sisteminde ise kompostlar $1 \mathrm{~m} \times 1.4 \mathrm{~m}$ ebatlarında olacak şekilde hazırlanmıştır. Çalışmada ele alınan torba ve blok pres torba yetiştirme sistemlerinin görünümleri Şekil 1'de verilmiş̧ir. Kompost miktarları her iki sistem için her bir tekerrürde eşit miktarda $(120 \mathrm{~kg})$ olacak şekilde ayarlanmıştır. Deneme, Tesadüf Parselleri deneme desenine göre 4 tekerrürlü olacak şekilde kurulmuştur (Gülümser ve ark., 2006).

Misel ön gelişme aşamasında üretim odasının sıcaklığı, kompost sıcaklığı $24-26^{\circ} \mathrm{C}$ olacak şekilde, yaklaşık 21 $24{ }^{\circ} \mathrm{C}^{\prime}$ ye ayarlanmıştır. Bu dönemde oda nemi \%90-95 civarında tutulmuştur. $\mathrm{CO}_{2}$ seviyesini yüksek tutabilmek için 
üretim odasına taze hava verilmemiş, oda içerisinde ısı dengesini sağlayabilmek için iç sirkülasyon yapılmıştır. Misel gelişimi tamamlandıktan sonra torba ve blok pres sisteminde kompost yüzeyleri tiftiklenip tokmaklanarak örtü toprağı serimi için hazır hale getirilmiştir. Bu işlemden sonra örtü toprağı $4-5 \mathrm{~cm}$ kalınlıkta olacak şekilde serilmiştir. Örtü toprağının seriminin 8. gününde tırmıklama işlemi yapıımışıı. Tırmıklama işleminden yaklaşık 2 gün sonra tırmıklanan örtü toprağının üzerinde kıılan miseller tekrar bağlanmaya ve gelişmeye başladığı an itibari ile oda sıcaklığı kademeli olarak 16-17 ${ }^{\circ} C^{\prime}$ ye düşürülmüştür. Soğutmaya alma dönemi olarak adlandırılan bu dönemde oda sıcaklığının yanında odanın $\mathrm{CO}_{2}$ seviyesi de yaklaşık 5000-6000 ppm'den 1750-2000 ppm seviyelerine düşürülmüştür. Tırmıklamadan yaklaşık 9-10 gün sonra mantar taslakları oluşmaya başlamış ve taslakların gelişimi ile flaş dönemi başlamıştır.

Verim miktarı 2 flaştan alınan mantar ağırlıkları ile tespit edilmiştir. Her hasatta alınan ürünün bir üretim dönemindeki toplam miktarı $100 \mathrm{~kg}$ kompost üzerinden hesaplanarak verim değerleri $\mathrm{kg}$ olarak belirlenmiştir $\left(\right.$ Verim $=\mathrm{kg}$ mantar $100 \mathrm{~kg}$ kompost $^{-1}$ ). Verim unsurları ile ilgili toplam mantar sayısı (adet), her bir tekerrürdeki $120 \mathrm{~kg}$ kompost üzerinden elde edilen değerlerin ortalamasıdır. Kalite özellikleri ile ilgili olarak ortalama mantar ağırlığı (g), şapka çapı, şapka yüksekliği, sap çapı ve sap uzunluğu Uzun (1996)'ya göre ölçülmüştür. Mantar eti sertliği $\left(\mathrm{kg} \mathrm{cm}^{-2}\right), 4 \mathrm{~mm}$ çapında uca sahip el tipi penetrometre ile tespit edilmiştir. Mantarların morfolojik ve sertlik özellikleri her uygulamanın tüm tekerrürlerinde rastgele seçilen 10 mantar örneğinde yapılan ölçümlerle tespit edilmiştir.
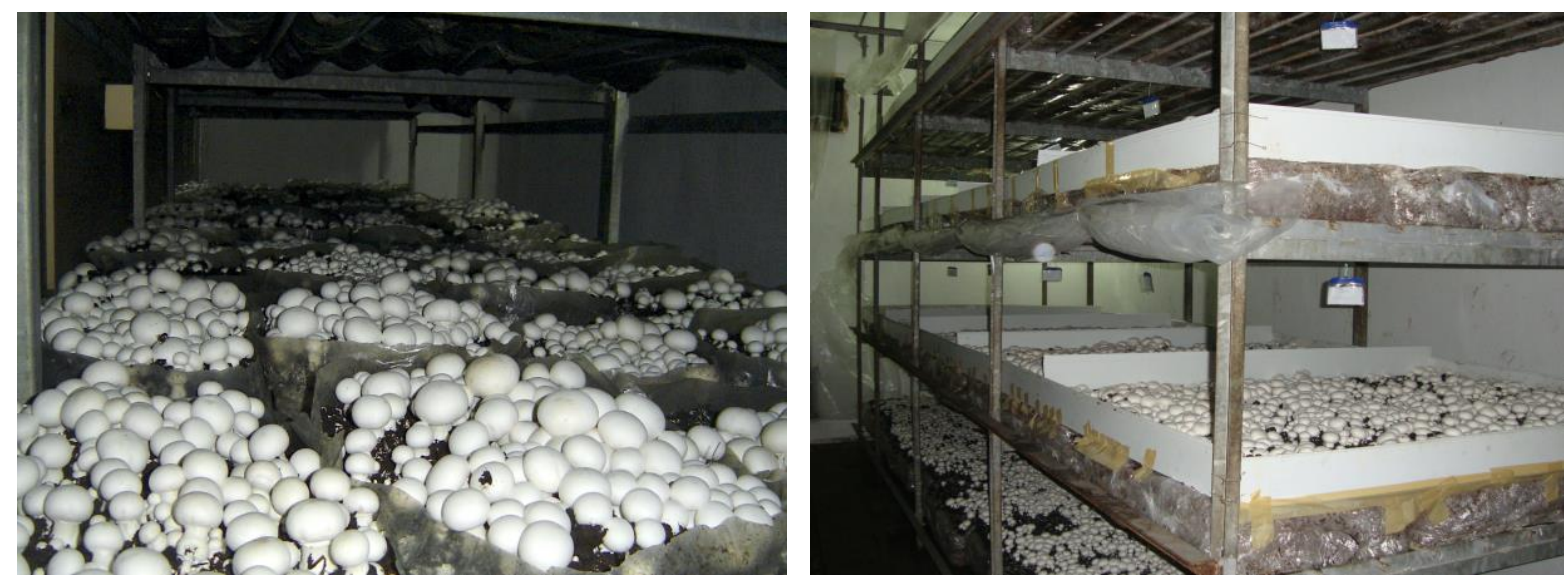

Şekil 1. Çalışmada kullanılan torba (solda) ve blok pres torba (sağda) yetiştirme sistemleri. Figure 1. Bag (left) and block press bag (right) growing systems used in the study.

Denemeden elde edilen verilerin SPSS (ver. 15.0 for Windows) istatistik programında varyans analizleri yapılmış, gruplandırmalarda Duncan çoklu karşılaştırma testi kullanılmıştır. Sonuçların istatistiksel değerlendirmelerinde farklar arasındaki önemlilik \% 5 olarak belirtilmiştir.

\section{BULGULAR VE TARTIŞMA}

Çalışmada torba ve blok pres yetiştirme sistemlerinde üretilen toplam mantar sayısı ve verim değerleri sırasıyla Şekil 2 ve 3'de, mantarların ortalama mantar ağırlığı, şapka çapı, şapka yüksekliği, sap çapı, sap uzunluğu ve sertlik değerleri ise Çizelge 1 'de verilmiştir.

Torba ve blok pres yetiştirme sistemlerinin toplam mantar sayısı üzerine etkisi önemli $(p<0.05)$ bulunmuştur. En yüksek toplam mantar sayısı blok pres sisteminden (172.17 adet), en düşük ise torba sisteminden (149.12 adet) elde edilmiştir (Şekil 2). 


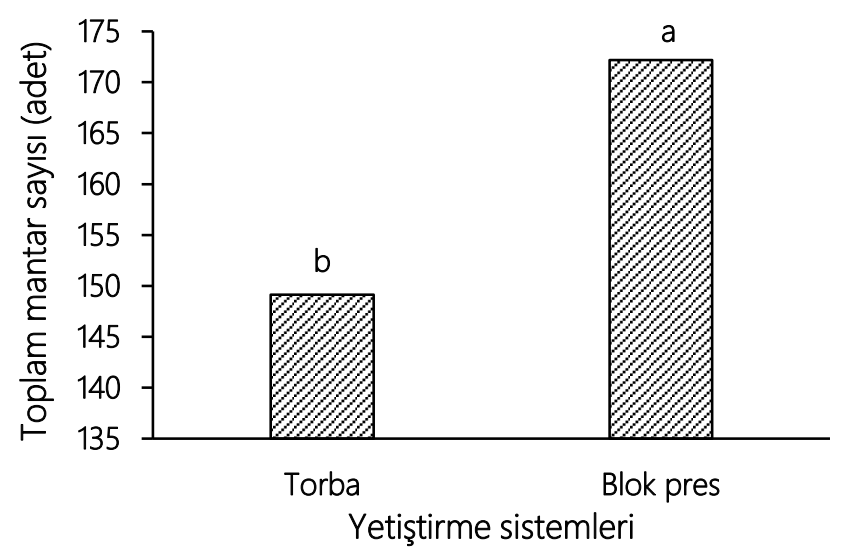

Şekil 2. Torba ve blok pres yetiştirme sistemlerinin Agaricus bisporus'un toplam mantar sayısı üzerine etkisi. Figure 2. The effect of bag and block press growing systems on the total fruit bodies number of Agaricus bisporus.

Yetiştirme sistemleri verim bakımından karşılaştııılığında aralarındaki fark istatistiksel olarak önemli bulunmuştur. Blok pres torba sisteminden elde edilen verim değeri (26.58 kg $\left.100 \mathrm{~kg} \mathrm{kompost}^{-1}\right)$, torba sisteminden elde edilen verim değerine (22.23 kg $\left.100 \mathrm{~kg} \mathrm{kompost}^{-1}\right)$ göre istatistiksel olarak önemli derecede yüksek bulunmuştur (Şekil 3). Verim değerleri arasındaki bu fark blok pres sisteminde elde edilen toplam mantar sayısının torba sistemine göre daha yüksek olmasından kaynaklanmaktadır (Şekil 2). Farklı amaçlarla beyaz şapkalı mantarda yürütülen çalışmalarda verim değerlerinin 4.25-26.74 kg $100 \mathrm{~kg} \mathrm{kompost}^{-1}$ olduğu bildirilmiştir (Pardo ve ark., 2004; Polat ve ark., 2008; Şimşek ve ark., 2008; Pekşen ve Günay, 2009; Eren ve Boztok, 2013; Çetin ve ark., 2016).

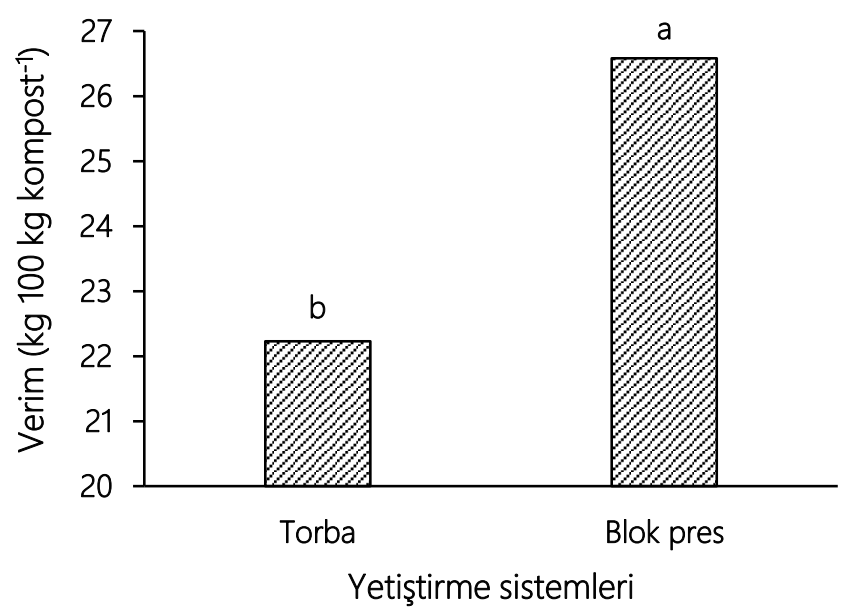

Şekil 3. Torba ve blok pres yetiştirme sistemlerinin Agaricus bisporus verimi üzerine etkisi.

Figure 3. The effect of bag and block press growing systems on the yield of Agaricus bisporus.

Yetiştirme sistemlerinden elde edilen mantarların ortalama ağırlıkları arasındaki fark ise istatistiksel olarak önemsiz bulunmuştur (Çizelge 1). Çalışmada elde edilen ortalama mantar ağırlıkları (17.89-18.54 g), çay atıklarının A. bisporus yetiştiriciliğinde kompost olarak kullanım durumunu inceleyen Pekşen ve Günay (2009)'ın elde ettikleri mantar ağırlıkları ile (15.14-21.16 g) benzerdir. Yadav ve ark. (2017), farklı örtü toprağı karışımlarının iki farklı $A$. bisporus ırklarının verim ve kalitesi üzerine etkilerini araştırdıkları çalışmada ortalama mantar ağılıklarının 11.66$32.00 \mathrm{~g}$ arasında değiştiğini bildirmişlerdir.

Çizelge 1. Torba ve blok pres yetiştirme sistemlerinin Agaricus bisporus mantarının özellikleri üzerine etkisi. Table 1. The effect of bag and block press growing systems on the characteristics of Agaricus bisporus mushroom.

\begin{tabular}{lllllll}
\hline $\begin{array}{l}\text { Yetiştirme } \\
\text { Sistemleri }\end{array}$ & $\begin{array}{l}\text { Ortalama } \\
\text { Mantar Ağırlığı } \\
(\mathbf{g})\end{array}$ & $\begin{array}{l}\text { Şapka Çapı } \\
\mathbf{( c m )}\end{array}$ & $\begin{array}{l}\text { Şapka } \\
\text { Yüksekliği } \\
(\mathbf{c m})\end{array}$ & $\begin{array}{l}\text { Sap Çapı } \\
\mathbf{( c m}\end{array}$ & $\begin{array}{l}\text { Sap Uzunluğu } \\
\mathbf{( c m )}\end{array}$ & $\begin{array}{l}\text { Sertlik } \\
\left(\mathbf{k g} \mathbf{~ c m}^{-2}\right)\end{array}$ \\
\hline Torba & 17.89 & 4.34 & $3.00 \mathrm{~b}^{*}$ & $1.86 \mathrm{a}^{*}$ & 2.09 & 1.99 \\
Blok pres & 18.54 & 4.23 & $3.17 \mathrm{a}$ & $1.75 \mathrm{~b}$ & 2.09 & 1.99 \\
\hline
\end{tabular}

*Farkıı harfle gösterilen ortalamalar arasındaki fark 0.05 düzeyinde önemlidir. 
Torba ve blok pres sistemlerinde mantarların şapka çapı değerleri arasındaki fark istatistiksel olarak önemsiz bulunmuştur. İki farklı üretim sisteminden elde edilen mantarların şapka çap değerleri torba sisteminde ortalama $4.34 \mathrm{~cm}$ ve blok pres sisteminde ise $4.23 \mathrm{~cm}$ olarak tespit edilmiştir (Çizelge 1). Şapka çapı ile ilgili elde edilen bulgular, Pekşen ve Günay (1998)'ın $(4.37$ ve $4.40 \mathrm{~cm}$ ) ve Kerketta ve ark. (2019)'nın $(3.99-4.50 \mathrm{~cm})$ bulgularıla uyumlu bulunmuştur. Eren ve Boztok (2013) tarafından farklı örtü toprağı materyalinin verim ve kalite kriterleri üzerine etkisinin incelendiği çalışmada kompostlar ortalama $12 \mathrm{~kg}$ 'ık torba sisteminde yetiştirilmiş olup, bu uygulamalarda mantarların şapka çapı değerlerinin 3.53-4.24 cm arasında değiştiği bildirilmiştir. Çalışmada şapka çap değerleri Yadav ve ark. (2017)'nın belirlediği şapka çapı (4.13-5.43 cm) ve Erdoğan ve ark. (2018)'nın belirlediği şapka çapı değerlerinden $(4.92-5.21 \mathrm{~cm})$ düşük bulunmuştur.

Şapka yüksekliği bakımından torba ve blok pres sistemleri arasındaki farkın istatistiksel olarak önemli $(p<0.05)$ olduğu saptanmıştır. Blok pres ile yapılan üretimde mantarların ortalama şapka yüksekliği $3.17 \mathrm{~cm}$, torba sistemi ile yapılan üretim sonrasında mantarların ortalama şapka yüksekliği ise $3.00 \mathrm{~cm}$ olarak belirlenmiştir (Çizelge 1). Elde edilen bulgular şapka yüksekliğinin 1.88-2.12 cm arasında değiştiğini bildiren Eren ve Boztok (2013)'un bulgularından daha yüksek bulunmuştur.

Torba sistemi ile yapılan üretimde mantarların sap çapı değerleri $(1.86 \mathrm{~cm})$, blok pres sistemine göre $(1.75 \mathrm{~cm})$ istatistiksel olarak önemli $(p<0.05)$ derecede yüksek bulunmuştur (Çizelge 1$)$. Sap çapı ile ilgili bulgularımız Günay ve Uzun (1996), Padem ve ark. (2003), Çetin ve Eren (2017) ve Erdoğan ve ark. (2018)'nın bulgularıyla (sırasıyla $1.69-1.98 \mathrm{~cm}, 1.96-3.11 \mathrm{~cm}, 1.78-1.80 \mathrm{~cm}$ ve $1.85-2.16 \mathrm{~cm}$ ) uyumludur.

İstatistiksel analiz sonucunda torba ve blok pres sistemlerinde mantarların sap uzunluğu değerleri arasındaki farkın önemsiz olduğu tespit edilmiştir. Çalışmada her iki sistemde mantarların ortalama sap uzunlukları $2.09 \mathrm{~cm}$ olarak belirlenmiştir (Çizelge 1). Elde ettiğimiz sap uzunluk değerleri, Yadav ve ark. (2017)'nin elde ettiğini bildirdiği sap uzunluk değerleri $(1.93-3.03 \mathrm{~cm}$ ) ile uyumlu bulunmuştur. Yapılan bazı çalışmalarda $A$. bisporus mantarının sap uzunluk değerlerinin 1.58-4.85 cm arasında değiştiği bildirilmiştir (Padem ve ark., 2003; Çetin ve Eren, 2017; Erdoğan ve ark., 2018).

Her iki sistemde de üretilen mantarların sertlik değerleri arasında istatistiksel olarak fark önemli bulunmamış ve sertlik değerleri $1.99 \mathrm{~kg} \mathrm{~cm}^{-2}$ olarak tespit edilmiştir (Çizelge 1). Sertlikle ilgili elde edilen bulgular, Lee ve ark. (2014)'nın iki farklı A. bisporus ırkında belirledikleri $5.25-5.76 \mathrm{~kg} \mathrm{~cm}^{-2}$ sertlik değerlerinden düşük bulunmuştur. Bununla birlikte çalışmada elde edilen sertlik değerlerinin farklı örtü materyallerinde yetiştirilen mantarların sertlik değerlerinin 1.42-3.87 kg cm${ }^{-2}$ olduğunu bildiren Duran (2021)'ın bulguları ile uyumlu olduğu görülmektedir.

\section{SONUÇ}

Çalışmada her iki yetiştirme sisteminden elde edilen mantarların özelliklerinin (şapka çapı, şapka yüksekliği, sap çapı ve uzunluğu, sertlik) pazarda tercih edilen optimum değerler arasında olduğu tespit edilmiştir. Bununla birlikte pazarlanabilir ürün üretimi yanında her iki yetiştirme sisteminin karşılaştııımasında en önemli parametre olan verim ve toplam mantar sayısı arasındaki fark önemli bulunmuştur (Şekil 2 ve 3). Üretim maliyetlerinin her geçen gün artmış olduğu ülkemizde, verim bakımından torba sistemine göre blok pres sistem ile elde edilen \%4.35 oranındaki verim artışı, işletmelerin üretim maliyetlerini azaltacağı gibi işletmenin toplam cirosunu, dolayısıyla karlılığını da yükseltmesi bakımından önemlidir.

Bu iki yetiştirme sistemini diğer yönleri ile karşılaştıracak olursak, blok pres sistemi mekanizasyona daha fazla imkan tanıyarak işçilik maliyetini azaltmaktadır. Nakliyesi daha kolaydır ve üretim odalarında yerleşimleri itibari ile birim alanda daha fazla kompost yerleşimine (daha fazla kullanım (üretim) alanına) imkan tanımaktadır. Ayrıca küçük üreticilerden büyük modern üretim tesislerine kadar hizmet sunabilme avantajına sahiptir. Diğer taraftan blok pres kompostlar ile yapılan üretimde kompostların tiftiklenmesi, örtü toprak serimi gibi kültürel işlemler için kullanılan işçilik maliyetlerinin düşük olması, bu sistemde yapılacak kültür mantarı üretiminde tercih nedeni olacaktır. Tüm bu sayılan avantajları nedeniyle blok pres ile hazırlanmış kompostlar sadece beyaz şapkalı mantar üretiminde değil, farklı mantarların üretiminde de yaygın olarak kullanılabilir.

Sonuç olarak çalışmada elde edilen verim ve kalite değerleri ile kullanımda sağladığı faydalar dikkate alındığında; blok pres torba sisteminin kullanııması üreticilere önemli avantajlar sağlayacaktır.

\section{ÇIKAR ÇATIŞMASI}

Yazarlar arasında çalışmanın planlanması, yürütülmesi ve makalenin yazılması konusunda herhangi bir çıkar çatışması bulunmadığını beyan ederiz. 


\section{YAZAR KATKISI}

Erkan Eren ve Mehmet Çetin denemenin yürütülmesi ve verilerin elde edilmesinde, Aysun Pekşen makalenin yazımında görev almıştır. Denemenin planlanması, verilerin istatistiksel analizleri ve sonuçların yorumlanmasında yazarlar birlikte katkı sağlamışlardır.

\section{KAYNAKLAR}

Çetin, M., \& Eren, E. (2017). Hacimsel olarak farklı oranlardaki torf ve pomza karışımının mantarın (Agaricus bisporus (Lange) Sing) verim ve kalitesi üzerine etkisi. Ege Üniversitesi Ziraat Fakültesi Dergisi, 54(2), 207-213.

Çetin, M., Özaktan, H., \& Boztok, K. (2016). Örtü toprağında bulunan bazı yararlı bakterilerin kültür mantarı Agaricus bisporus'un gelişim ve verimi üzerine etkileri. Türk Tarım-Gıda Bilim ve Teknolojisi Dergisi, 4(3), 197-203.

Duran, H. (2021). Farklı atık materyallerin mantar yetiştiriciliğinde örtü toprağı olarak kullanım olanakları. Doktora Tezi, Ondokuz Mayıs Üniversitesi Lisansüstü Eğitim Enstitüsü, Samsun.

Erdoğan, F., Paksoy, M., Seymen, M., \& Türkmen, Ö. (2018). Farklı sıcaklık uygulamalarının mantarda (Agaricus bisporus (Lange) Sing.) verim ve karpofor özellikleri üzerine etkileri. Manas Journal of Agriculture Veterinary and Life Sciences, 8(2), 70-77.

Eren, E., \& Boztok, K. (2013). Farklı artık materyallerin Agaricus bisporus mantar üretiminde örtü toprağı olarak kullanılabilme olanakları. Iğdır Üniversitesi Fen Bilimleri Enstitüsü Dergisi, 3(1), 9-16.

Eren, E., \& Pekşen A. (2019). Türkiye'de kültür mantarı üretimi ve teknolojik gelişmeler. Mantar Dergisi, 10, 225-233.

Eren, E., Öztekin, G.B., \& Tüzel, Y. (2016). Türkiye'de orta ve büyük ölçekli mantar işletmelerinin değerlendirilmesi. Türk TarımGıda Bilim ve Teknoloji Dergisi, 4(3), 230-238.

Erkal, S., \& Aksu, Ş. (2000). Türkiye'de kültür mantarı sektöründeki geliş̧meler ve işletmelerin yapısal özellikleri. Türkiye 6. Yemeklik Mantar Kongresi, Bergama, İzmir.

Gülümser, A., Bozoğlu, H., \& Pekşen, E. (2006). Araştırma ve Deneme Metotları. Ondokuz Mayıs Üniversitesi, Ziraat Fakültesi, Ders Kitabı, 48.

Günay, A. (1995). Mantar Yetiştiriciliği. Illke Kitap ve Yayınevi, Ankara. ISBN:975-7923-15X

Günay, A., \& Uzun, A. (1996). Buğday sapı ve tavuk gübresinin esas alındığı değişik yetiştirme ortamlarının mantarın (Agaricus bisporus) verim ve kalitesi üzerine etkileri. Türkiye 5. Yemeklik Mantar Kongresi, Yalova.

Kerketta, A., Shukla, C. S., \& Singh, H. K. (2019). Evaluation of different casing materials for growth and yield of buton mushroom (Agaricus bisporus (L.) Sing.). Journal of Pharmacognosy and Phytochemistry, 8(4), 207-209.

Lee, B. J., Lee, M. A., Kim, Y. G., Lee, K. W., Lee, B. E., \& Song, H. Y. (2014). Varietal characteristics of new white button mushroom 'Seolwon' in Agaricus bisporus. Journal of Mushrooms, 12(2), 82-87.

Padem, H., Ünlü, H., \& Takka, H. (2003). Agaricus bisporus üretiminde ağaç işleme sanayi atık maddeleri ve humik asit uygulamalarının verim ve kaliteye etkisi. Ekoloji Çevre Dergisi, 12(46), 8-11.

Pardo, A., De Juan, A. J., Pardo, J., \& Pardo, J. E. (2004). Assesment of different casing materials for use as peat alternatives in mushrom cultivation. Evaluation of quantitative and qualitative production parameters. Spanish Journal of Agricultural Research, 2(2), 267-272.

Pekşen, A. U., \& Günay, A. (1998). Çeltik ve buğday sapının değişik oranlarda karışımlarından hazırlanan kompostların mantarın (Agaricus bisporus L.) verim ve kalitesi üzerine etkileri. 2. Sebze Tarımı Sempozyumu, Tokat.

Pekşen, A., \& Günay, A. (2009). Kültür mantarı (Agaricus bisporus (L.) Sing.) yetiştiriciliğinde çay atığı ve buğday sapı karışımından hazırlanan kompostların kullanımı. Ekoloji Dergisi, 19(73), 48-54.

Polat, E., Erler, F., Demir, H., Cetin, H., \& Erdemir, T. (2008). The effect of vegetable materials on the yield and productivity of Agaricus bisporus. Interciencia, 33(10), 776-780.

Samp, R. (2017). The bag or block system of Agaricus mushroom growing. Edible and Medicinal Mushrooms: Technology and Applications, 175-195.

Şimşek, H., Baysal, E., Çolak, M., Toker, H., \& Yılmaz, F. (2008). Yield response of mushroom (Agaricus bisporus) on wheat straw and waste tea leaves based composts using supplements of some locally available peats and their mixture with some secondary casing materials. African Journal of Biotechnology, 7, 88-94.

Uzun, A. (1996). Karadeniz bölgesinde kültür mantarı (Agaricus bisporus (Lange) Sing.) üretiminde kullanılabilecek organik materyallerin tespiti ile bunların mantarın verim ve kalitesine etkisi üzerine bir araştırma. Doktora Tezi, Ondokuz Mayıs Üniversitesi Fen Bilimleri Enstitüsü, Samsun, 
Eren ve ark., Torba ve Blok Pres Yetiştirme Sistemlerinin Agaricus bisporus Mantarının Verim ve Morfolojik Özellikleri Üzerine Etkisi

Yadav, M. K., Ram, C., Yadav, S. K., Dhakad, P. K., Srivastava, A. K., Dwivedi, P. K., \& Sushreeta, N. (2017). Comparative evaluation of locally available casing materials for quantitative and qualitative effect on two strains of Agaricus bisporus (Lange). Biochemical and Cellular Archives, 17(1), 133-139. 